\title{
In the Days of Beginning Global Warming: Cool Is Beautiful
}

\author{
Andreas Sputtek ${ }^{\mathrm{a}} \quad$ Allison Hubel ${ }^{\mathrm{b}}$ \\ a Institut für Transfusionsmedizin, Universitätsklinikum Hamburg-Eppendorf, Hamburg, Germany \\ ${ }^{b}$ Department of Mechanical Engineering, University of Minnesota, Minneapolis, MN, USA
}

When blood is withdrawn from a human being, this is the beginning of hypothermia - provided this is not done at ambient temperatures at or above $37{ }^{\circ} \mathrm{C}$ (i.e. $98.6{ }^{\circ} \mathrm{F}, 370 \mathrm{~K}$ ). The same holds for any tissue or organ removed at room temperature. This removal is already the start of a sometimes not very well controlled cooling process; it is the first step towards hypothermia, which is characterized by a lowering of biochemical and biophysical reaction rates. For biochemical reactions, this relationship is well described by the Arrhenius law, which can be written in various forms, one of which is

$$
\mathrm{k}=\mathrm{A} \mathrm{e}-\mathrm{E} / \mathrm{RT}
$$

where $\mathrm{T}$ is the absolute temperature, $\mathrm{A}$ is a constant, $\mathrm{E}$ is the activation energy of the reaction and $\mathrm{R}$ is the gas constant. Thus, an Arrhenius plot of $\ln \mathrm{k}$ as a function of $1 / \mathrm{T}$ yields a straight line with slope -E/R. However, in a sequence of reactions each step may have a different activation energy which makes the overall effect of a change in temperature quite unpredictable.

Keeping this in mind, what happens to a mammalian organism when controlled cooling down to $6{ }^{\circ} \mathrm{C}$ in parallel to exsanguination is performed, followed by an asanguineous perfusion by special blood substitution fluids for several hours, and controlled rewarming? This is described in the article by Taylor [1] in this issue. The good news for people in the field of transfusion medicine is that blood was needed again after the rewarming and that the dogs were not able to play chess afterwards (nor had they been before). However, in times of an existing shortage of red cells for transfusion, the demonstrated efficacy of these synthetic, acellular solutions justifies their consideration for multiple organ harvesting from cadaveric brain-dead heart-beating donors.

From a protein's point of view the removal from a 'warm' organism is the beginning of dampening of the molecular motions and the elimination of conformational transitions - in other words, denaturation. The structure of a protein is determined by intermolecular and intramolecular interactions, such as Van der Waals interactions as well as polar, hydrogen and ionic bonds. When we cool, e.g. fresh frozen plasma, we reduce the activity of the surrounding water, and we expose the proteins to solutes that may alter their chemical activities and affect their secondary and tertiary structure. Fortunately most of the proteins intended for a later use in patients (e.g. to stop bleeding) seem to tolerate this well, provided we freeze the plasma rapidly, store it at sufficiently low temperatures and rewarm it quickly. The article by Ragoonanan and Aksan [2] in this issue reviews the methods we have at present for protein stabilization and proposes a new stabilization method termed 'nanoencapsulation'.

On a cellular level, the removal of a cell, tissue, or an organ from a living organism is the start of hypoxemia as well, and in combination with hypothermia both effects may lead to cell, tissue, and organ damage. So why not simply keep the temperature at the level it is inside the organism? The answer is that slowing down biophysical and biochemical reactions may be what we want to achieve when hypoxemia takes place. As a rule of thumb, oxygen consumption is halved for each $10{ }^{\circ} \mathrm{C}$ drop in temperature. Another answer is that we want to make life less comfortable for contaminating microbiological 'guests' once the biological material is not 'safe-guarded' by a fully functional immunological system. Both answers apply to the storage of red cells for transfusion at $4{ }^{\circ} \mathrm{C}$ : They are not expected to perform a lot of anaerobic glycolysis. Generally this requires a temperature (mostly found empirically by trial and error) which is not too low for the target cell, tissue or organ but low enough for the undesired microbes. However, it is known that the activity of the Na-K pump in human erythrocytes at $5{ }^{\circ} \mathrm{C}$ is only $0.25 \%$ of that at $37^{\circ} \mathrm{C}[3]$. The rate of ion pumping at such low temperatures is unable to match the passive ion fluxes and there is a net gain of $\mathrm{Na}^{+}$and $\mathrm{Cl}^{-}$(asso-

\begin{tabular}{ll}
\hline KARGER & @ 2007 S. Karger GmbH, Freiburg \\
Fax +497614520714 & Accessible online at: \\
$\begin{array}{l}\text { E-mail Information@Karger.de } \\
\text { www.karger.com }\end{array}$ & www.karger.com/tmh
\end{tabular}

Dr. Andreas Sputtek 
ciated with a $\mathrm{K}^{+}$loss) which osmotically draws in water and leads to cell swelling. As a consequence the hematocrit in stored red cell units increases towards the end of the storage period. On the other hand, platelets for transfusion are stored at room temperature in gas-permeable bags under agitation because platelets need oxygen for their aerobic glycolysis. They also need to get rid of the carbon dioxide produced as a result thereof: Otherwise the resulting drop in $\mathrm{pH}$ leads to their inactivation. The work by Josefsson et al. [4] in this issue is an example of how complex the phenomena are when chilling platelet concentrates to different temperatures and for different periods of time. They propose a mechanism which explains the fact why chilled platelets are rapidly removed from circulation despite high functionality and also propose methods for intended ex vivo preservation.

There is no doubt that there is a growing interest in how to harness the natural ability of living cells to survive another unfriendly treatment: freezing. Cryopreservation of somatic and reproductive cells and tissues has a wide range of applications in biotechnology, biomedicine, agriculture, forestry, aquaculture, biodiversity conservation and - transfusion medicine. The cryopreservation of blood cells can be regarded as a classical field of development and application of low temperature biology. The review by Sputtek et al. [5] summarizes from where we have progressed to where we are now. New concepts are being derived from the growing appreciation of the use of polymeric extracellular cryoprotectants. Cellular therapies based on the use of hematopoietic stem cells either from bone marrow or peripheral blood have become a standard therapy for a variety of diseases, and some transfusion medicine-based institutions were fortunate and clever enough not to miss this train. The article by Fleming and Hubel [6] summarizes the emerging science, technology and issues in this field regarding aspects of cryopreservation. In their paper, Woods et al. [7] summarize what is known about procedures for cord blood stem cell cryopreservation. While umbilical cord blood has been known to be a rich source of hematopoietic stem cells capable of providing hematopoietic reconstitution, more recently it has also been investigated as a potential source of mesenchymal stem/progenitor cells. Under correct cytokine stimulation, these cells exhibit the mesenchymal lineage capacity to form bone, fat and cartilage. They are usually prepared and cryopreserved using methods prescribed for hematopoietic progenitor preservation; optimized methods specific to this cell type have yet to be fully investigated.

From an 'evolutionary' perspective, blood banking can be regarded as a first step to tissue and organ banking. Patients will increasingly benefit from donated bone, cartilage, corneas, skin grafts and heart valves. People running a blood bank are experts in organizational requirements (e.g. record keeping and working in accordance with standard operating procedures), acquisition (e.g. ethical and legal rules, anonymity, donor screening and selection), processing (e.g. identification, inspection, storage, expiration, irradiation, sterilization, freeze-drying, quality management), labeling, distribution, and transportation. The above-mentioned prerequisites are already implemented in a modern blood bank, so why not take the chance as described in the contribution by Rebulla et al. [8] in this issue to diversify into a 'biobank'?

Today, 'Life and Death at Low Temperatures' (with a bow to Basil Luyet and his 1940 famous book) [9] would not be complete without an article about the banking of human embryonic stem cells. Pluripotent human embryonic stem cells tend to differentiate into cells from all 3 germ layers when being kept in culture. Therefore, an essential prerequisite for the development of treatments with these cells is setting up banks of well-characterized and safety-tested cells for research - and even more important for therapeutic applications. Currently conventional freezing (rather low concentrations of cryoprotectants and slow cooling) or vitrification (high concentrations of cryoprotective cocktails and extremely rapid cooling) have been applied with varying degrees of success. The article by Hunt [10] reviews the debate and describes the current practice at the UK Stem Cell Bank.

Finally: We want to emphasize that our underlying scientific discipline, termed 'cryobiology', does not subscribe to, and in fact views with skepticism, the practice of 'cryonics'. The practitioners of cryonics freeze entire bodies or detached heads of deceased persons in anticipation of their reanimation to a normal living individual, a practice which has no scientific basis. To paraphrase Arthur W. Rowe, co-author of [4] (personal communication): 'Believing that cryonics could result in reanimation of a human being after having been frozen is like believing you could turn hamburger back into a cow'.

\section{References}

1 Taylor MJ: Hypothermic blood substitution: special considerations for protection of cells during ex vivo and in vivo preservation. Transfus Med Hemother 2007;34(4):226-244.

2 Ragoonanan V, Aksan A: Protein stabilization. Transfus Med Hemother 2007;34(4):246-252.

3 Willis JS, Ellory JC, Wolowyk MW: Temperature sensitivity of the sodium pump in red cells from various hibernator and non-hibernator species. J Comp Physiol 1980;138:43-47.
4 Josefsson EC, Hartwig JH, Hoffmeister KM: Platelet storage temperature - how low can we go? Transfus Med Hemother 2007;34(4):253-261.

5 Sputtek S, Kühnl P, Rowe AW: Cryopreservation of erythrocytes, thrombocytes and lymphocytes. Transfus Med Hemother 2007;34(4):262-267.

6 Fleming KK, Hubel A: Cryopreservation of hematopoietic stem cells: emerging science, technology and issues. Transfus Med Hemother 2007; 34(4):268-275.
$>7$ Woods EJ, Pollok KE, Byers MA, Perry BC, Heimfeld S, Gao D: Cord blood stem cell cryopreservation. Transfus Med Hemother 2007;34(4):276-285.

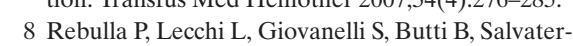
ra E: Biobanking in the year 2007. Transfus Med Hemother 2007;34(4):286-292.

9 Luyet BJ, Gehenio PM: Life and Death at Low Temperatures. Normandy, Biodynamica, 1940.

10 Hunt JH: The banking and cryopreservation of human embryonic stem cells. Transfus Med Hemother 2007;34(4):293-304. 